Research Article

\title{
Knowledge, Attitude, and Practice of Provincial Dwellers on Prevention and Control of Schistosomiasis: Evidence from a Community-Based Cross-Sectional Study in the Gambia
}

\author{
Amadou Barrow (D, ${ }^{1,2}$ Mansour Badjie, ${ }^{1}$ Jainaba Touray, ${ }^{1}$ Bakary Kinteh, ${ }^{1}$ Musa Nget, \\ Ebrima Touray, ${ }^{1}$ Sambou L. S. Kinteh, ${ }^{1}$ Saikou Omar Sillah, ${ }^{1}$ Lamin Darboe, ${ }^{1}$ \\ Yunusa Jallow, ${ }^{1}$ Modou Badjan, ${ }^{1}$ Modou Gaye, ${ }^{1}$ and Solomon P. S. Jatta ${ }^{1}$ \\ ${ }^{1}$ School of Public Health, Gambia College, Brikama, Gambia \\ ${ }^{2}$ Department of Public \& Environmental Health, School of Medicine \& Allied Health Sciences, University of the Gambia, \\ Kanifing, Gambia \\ Correspondence should be addressed to Amadou Barrow; flexybams@gmail.com
}

Received 15 February 2020; Accepted 23 May 2020; Published 29 June 2020

Academic Editor: Pedro P. Chieffi

Copyright (c) 2020 Amadou Barrow et al. This is an open access article distributed under the Creative Commons Attribution License, which permits unrestricted use, distribution, and reproduction in any medium, provided the original work is properly cited.

\begin{abstract}
Background. Socioeconomically disadvantaged and neglected communities were found to be the most affected groups for schistosomiasis as a result of inadequate safe water and sanitation facilities. In order to inform policies and practices, the present study examined the influence of sociodemographic factors and attitudes on the knowledge and practice in the prevention and control of schistosomiasis in eighteen endemic rural communities in the Gambia. Methods. In January 2019, a community-based cross-sectional study was conducted in which 383 household heads in rural communities across Kuntaur and Janjanbureh Local Government Areas (LGAs) in Central River Region were recruited. A structured interview questionnaire was developed to elicit information regarding residents' knowledge, attitude, and practice on schistosomiasis prevention and control measures. Percentages, chi-square test, and binary and multiple logistic regression models were used to identify sociodemographic factors associated with the KAP variables. The significance level was set at $p<0.05$. Results. Among the 383 participants, only $14.9 \%$ had good knowledge, while $54.3 \%$ had poor knowledge, $96.9 \%$ had positive attitude, and $57.7 \%$ had good practice towards prevention and control of schistosomiasis. Older age ( $\geq 40$ years), compared with residents aged $30-39$ years (AOR $=0.331 ; 95 \%$ CI: 0.133 , $0.825)$; ever heard of bilharziasis ( $\mathrm{AOR}=11.911 ; 95 \% \mathrm{CI}$ : 3.452, 41.099); and risks of contact with the polluted river $(\mathrm{AOR}=0.101$; $95 \%$ CI: $0.042,0.242$ ) were more likely to have good knowledge on schistosomiasis prevention and control in the rural Gambia. Conversely, young people ( $\leq 30$ years), compared with residents aged $\geq 40$ years (AOR $=2.503 ; 95 \% \mathrm{CI}=1.539,4.071)$; residents aged $30-39$ years $(\mathrm{AOR}=2.880 ; 95 \% \mathrm{CI}=1.559,5.320)$; and male residents $(\mathrm{AOR}=2.631 ; 95 \% \mathrm{CI}=1.703,4.067)$ were more likely to have good practice towards schistosomiasis prevention and control in the rural Gambia. Conclusion. Despite the low knowledge, rural dwellers' attitudes were found to be positive with slightly good practice towards schistosomiasis prevention and control measures. Thus, while maintaining health system improvement strategies, disease control efforts should focus on these factors as they may influence the knowledge and practices of rural dwellers in a given setting. The findings could prompt appropriate policy responses towards improving the knowledge and practices on schistosomiasis prevention and control in the Gambia.
\end{abstract}

\section{Background}

Schistosomiasis, widely referred to as bilharzia, continues to be a public health issue in many parts of the world, especially in Africa. It is predicted to cause over 200,000 deaths per annum globally and a minimum of $90 \%$ of individuals living in Africa who require treatment [1]. Additionally, estimates show that a minimum of 220.8 million people needed 
preventive treatment for schistosomiasis in 2017, out of which more than 102.3 million individuals have been said to be treated [2]. Sub-Saharan Africa accounts for over $85 \%$ of people living with schistosomiasis in a population that only constitutes $13 \%$ of the world's population [3]. Worldwide, there are six species of schistosomes that have an effect on people [4]. In SSA, S. haematobium and S. mansoni are the most popular species that cause urogenital and intestinal schistosomiasis, respectively [5].

The continuous burden of schistosomiasis in SSA along with its surprising and lifelong consequences may lead to debilitating and permanent clinical complications such as ulceration, blockage of the kidneys, enlargement of the liver and spleen, and barrenness [6]. Children, women, and those who work in contact with natural water bodies tend to be at higher risk across the SSA [7]. Scholars argue that success in schistosomiasis prevention among these groups can lessen the pace of transmission among the population [8]. As a result, their risk of infections was influenced by the poor sanitation status, lack of information, precarious water practices, and negative perspectives about schistosomiasis likewise as low women's educational status [9].

The national prevalence of schistosomiasis (SCH) and soil-transmitted helminthiasis (STH) in the Gambia was 4.3 percent and 2.5 percent, respectively. Schistosomiasis is prevalent in the district of Niani with a prevalence of $22 \%$, while Banjul had the highest prevalence of $55 \%$ for soiltransmitted helminthiasis [10]. Schistosoma haematobium is the most dominant parasitic infection in the Gambia. Coendemicity for both types constituted $38 \%$ of all districts in the country [10]. Most schistosomiasis educational programs target children who go to school because they are easy to reach, and the degree of such impact varies with the limited continuity of activities over a period of time according to community settings [11].

Population-based health education programs, improved sanitation, and routine mass drug administration remain key-controlled interventions for both SCH and STH [12]. Certain infection control strategies provide access to safe drinking water, proper sanitation, and the promotion of hygiene activities [13]. These interventions are critical in preventing or controlling SCH and STH. Owing to minimal sensitization, the majority of rural dwellers often mixed $\mathrm{SCH}$ and STH modes of transmission and prevention. Therefore, it is necessary to combine schistosomiasis and STH prevention measures to ensure that consistent messages about health education are formulated and disseminated. The effectiveness of a community-based control initiative depends on the program's approval by the community [14]. Thus, understanding the knowledge, attitude, and practice (KAP) of rural communities towards $\mathrm{SCH}$ and $\mathrm{STH}$ is a requirement for quality control program implementation. The functional role of the household head remains very critical at the community level $[13,15]$.

The paper contributes to the knowledge in order to shape policy decisions in the Gambia regarding the involvement of the general population in endemic communities on strategies for prevention and control of schistosomiasis. Therefore, it is important to explore and identify factors influencing communities' knowledge, attitude, and practice on the prevention and control of schistosomiasis as such information is required in the design and implementation of schistosomiasis intervention programs in the Gambia.

\section{Methods}

2.1. Study Area. The study was conducted in the Central River Region (CRR) of the Gambia which is divided into two main Local Government Areas (LGAs): Janjanbureh and Kuntaur. Janjanbureh LGA has its administrative headquarters at Janjanbureh, with a population of 126,910. It has a male population of $48.1 \%(60,001)$ and a female population of $51.9 \%(65,909)$ with a fertility rate of $7.0 \%$ [16]. The LGA has five districts, and the major occupations in the region include farming and business. The region has one major health center and four minor health centers. The main referral point for this region is Bansang General Hospital. Kuntaur LGA has its administrative headquarters at Kuntaur, with a population of 99,108 . It has a male population of $47.7 \%(47,233)$ and a female population of $52.3 \%(51,875)$ with a fertility rate of $7.2 \%$ [16]. This LGA has five districts, and the major occupations in the region include farming and business. The LGA has one district/major health center and four minor health centers. Bansang General Hospital is the main regional referral point [16].

The Gambia lies within the tropical subhumid ecoclimatic zone, with the rainfall range between 800 and $1200 \mathrm{~mm}$ annually [17]. The climate is characterized by two seasons, a wet season (between June and October) and a dry season (November to April), which is six to seven months of no rains [18]. During the dry season, the climate is dominated by dry and dust-laden winds that originate from the Sahara Desert in the northeast [17]. The Central River region has the highest rates of under-five mortality and malnutrition rates and access to improved water sources, and sanitation remains a major challenge [16]. Janjanbureh being an administrative headquarter of CRR that has about $30 \%$ of the population is using unimproved sources of water for drinking. The region registered high malnutrition rates among under-five children at $38 \%$ as a result of poor access to safe drinking water and sanitation [16]. The literary rate for men and women in CRR is $50.7 \%$ and $26.7 \%$, respectively [19]. The net enrolment rate for males was $41.1 \%$, while it was $37.0 \%$ for females [20]. The study was conducted in the first half of January 2019.

\subsection{Study Design, Population, and Participant Selection.}

The study was a community-based cross-sectional design with a focus on understanding the influence of sociodemographic characteristics and attitudes of rural dwellers' knowledge and practices on the prevention and control of schistosomiasis in CRR. The questionnaire was administered to heads of households of the eighteen identified hotspot communities in the region. A multistage sampling approach was used to select communities in both LGAs within CRR through proportionate sampling; randomization was used to select 18 endemic communities. At the final stage, another 
proportionate simple random sampling was used to recruit 383 participants from the 18 selected communities. The study involved rural dwellers who were 15 years old and above and willing to participate in the study. However, those who were identified as mentally challenged were exempted from the study.

2.3. Sample Size. In estimating the sample size of the study population, the current national prevalence of schistosomiasis of $4.3 \%$ was used [10]. The required sample size of 383 household heads was calculated using Dobson's formula as follows. The sample size was calculated using the single proportion formula:

$$
n=p q\left(\frac{z_{\propto / 2}}{e}\right)^{2}
$$

where $Z$ is the $Z$-value for the $95 \%$ confidence interval; that is, alpha $=5 \%(z=1.96), p$ is the proportion/prevalence of the outcome to be investigated $(p=0.043), q=1 ; p=0.957, e$ is the precision for the given confidence interval expected expressed as a decimal $(d=0.05)$, and $n=64$. The computed sample size was adjusted for $10 \%$ nonresponses and a design effect of 5.2 which resulted in 383 household heads participating in the survey.

2.4. Interview Using the Questionnaire. The interview questionnaire was written in English language and contains both closed and open-ended questions. The draft questionnaire was cast from the English language to core local languages (Mandinka, Fula, and Wolof) and later translated back to the English language in order to ensure consistency and enhance its applicability in various contexts. The tool was pretested for reliability and validity prior to the actual data collection. The validated survey questionnaire sourced information ranging from participants' sociodemographic characteristics, attitudes, practices, and knowledge on the prevention and control of schistosomiasis from all recruited household heads in the study.

2.5. Measurement of Outcome Variables. The outcome variables of the study were participants' knowledge and practice towards schistosomiasis. The explanatory variables were selected sociodemographic and attitudinal items. Principal component analysis (PCA) was used to assign the knowledge, practice, and attitude indicator weights. Furthermore, regarding knowledge on schistosomiasis, items used are heard about bilharziasis, source of information, symptoms, causes, and prevention measures. Using PCA, the standardized $\mathrm{z}$-score was used to disentangle the overall assigned scores to poor $(<50.0 \%)$, fair $(50.0 \%-59.9 \%)$, and good $(\geq 60.0 \%)$. Regarding practice towards schistosomiasis, items used are urination in water, swimming in the river, boiling of water, the frequent crossing of rivers, open defecation, etc. Using percentage scores for the selected items, the overall assigned scores were classified into good $(\geq 50.0 \%)$ and poor practice $(<50.0 \%)$. Similarly, attitude towards schistosomiasis used the following items: the disease being part of normal growth, toilet utilization, learning the disease at school, antibilharzia deworming utilization, play in the water, etc. Using percentage scores for the selected items, the overall assigned scores were classified into positive $(\geq 50.0 \%)$ and negative $(<50.0 \%)$ attitude.

2.6. Ethical Consideration. Prior to the commencement of the study, approval was obtained from the community leaders, Bansang Regional Health Directorate of the Ministry of Health, the Gambia. Ethical clearance for the study was provided by the Gambia College Research Committee. Community visits were made to the various communities in the area, engaging the village heads and village health workers in the communities. The people were sensitized about the nature of the study and study objectives in local languages (Mandinka, Fula, and Wolof). Written informed consent was obtained from each study participant for their enrolment into the study. Participation was entirely voluntary and only those that accepted to participate were recruited for the program.

2.7. Data Analysis. The collinearity testing approach adopted the diagnostic analysis to detect interdependence between variables. A cutoff of 0.7 was used to examine the multicollinearity known to cause major concerns . Participants' characteristics were obtained using percentages. The chi-square test was used to examine the association between knowledge, practice, and the explanatory variables. All variables with $p<0.20$ including significant variables from the bivariate analysis were included in the multivariable logistic regression model to calculate the adjusted odds ratios (AOR) with corresponding 95\% CI.

\section{Results}

3.1. Characteristics of Residents. A total of 383 residents in the Central River Region were recruited for the study. The sample was proportionately selected across 18 hotspot communities in the region and presented as follows: Kuntaur Fula Kunda (29.2\%), Kuntaur (12.3\%), Saruja (6.5\%), Wassu (13.3\%), Bantanto (11.0\%), Madina (5.7\%), Wellingara (3.7\%), Jakaba Manneh Kunda, and Mabally were (2.9\%) each; Jahaly Madina (3.4\%), Fuladu (2.1\%), Ndakaru (1.6\%), Boraba (1.8\%), Wally Kunda (0.5\%), Fula Kunda, and Jahali and Mbari were $(0.3 \%)$ each.

The mean age of the residents was 33.9 years with a standard deviation of 14.5. Participants below 30 years (47.0\%) and 40 years and above (32.9\%) accounted for the highest age group in the distribution. There was almost equal representation of gender in the study, while $96.3 \%$ were reported to be Muslims. In terms of proximity to the river, $84.9 \%$ reported that their homes are close to the river and only $62.9 \%$ stated the distance to be within 2 kilometers. Almost half of the residents (49.0\%) reported contact with polluted river water with feces/urine as the main risk factor for contracting bilharziasis, followed by $37.1 \%$ accounting for those who do not know any of the risk factors for contracting bilharziasis. Slightly more than half of the study 
participants $(57.9 \%)$ reported contaminated fecal/urine water/river as a source of bilharziasis. With regard to their opinion on important methods for the prevention of schistosomiasis, $45.3 \%$ revealed that they do not know any methods/approaches. Poor appetite (42.1\%) and skin infection $(42.1 \%)$ were reported for the common complications observed as a result of bilharziasis. The use of an herb called "Sinjango" and maintaining good hygiene was among the popular approaches for the management of bilharziasis with $83.6 \%$ and $81.5 \%$, respectively. At the level of bivariate analysis, residents' characteristics that were found to be significantly associated $(p<0.05)$ with knowledge on schistosomiasis are presented in Table 1.

\subsection{Multivariable Logistic Regression Model for Predicting} Knowledge on Schistosomiasis. The results of predicting residents' knowledge on schistosomiasis prevention and control showed that the likelihood of residents between 30 and 39 years of age decreased significantly by $66.9 \%$ to have good knowledge on schistosomiasis prevention and control compared to those of 40 years of age and above who had poor knowledge on schistosomiasis prevention and control (AOR $=0.331 ; 95 \% \mathrm{CI}: 0.133,0.825)$ as shown in Table 2 . Residents who had ever heard of bilharziasis were 11.911 times more likely to have good knowledge of schistosomiasis prevention and control compared to those who had never heard of bilharziasis in the category of poor knowledge on schistosomiasis prevention and control (AOR $=11.911 ; 95 \%$ CI: 3.452, 41.099). In addition, residents who opined that contact with the polluted river with feces/urine were less likely to have good knowledge by $89.9 \%$ as opposed to those who do not know about the specific risk factors for contracting bilharziasis in the category of poor knowledge on schistosomiasis prevention and control $(\mathrm{AOR}=0.101 ; 95 \%$ CI: $0.042,0.242)$.

Association of knowledge, attitude, and practice on prevention and control of schistosomiasis in CRR, the Gambia, is shown in Table 3.

As shown in Table 3, the greater proportion of the residents (96.9\%) were found to have a positive attitude towards schistosomiasis prevention and control while slightly more than half of the residents (57.7\%) adopted good practice towards schistosomiasis prevention and control at the time of the study. There was no statistically significant association between residents' attitude, practice, and knowledge on schistosomiasis prevention and control at $(p=0.712)$ and $(p=270)$, respectively.

3.3. Attitude of Participants towards Schistosomiasis Prevention and Control. Table 4 explores the association between attitude and selected sociodemographic variables, and none were found to be statistically significant.

3.4. Participants' Practice towards Schistosomiasis Prevention and Control. In terms of the association between practice towards schistosomiasis with selected sociodemographic variables, age and gender of the residents were found to be statistically significant at $(p=0.001)$ and $(p<0.001)$, respectively, as shown in Table 5 .

\subsection{Multivariable Logistic Regression Model for Predicting} Practice on Schistosomiasis Prevention and Control. The model (Table 6) predicted that residents below 30 years of age were 2.503 more likely to have good practice towards schistosomiasis prevention and control compared to those of 40 years of age and above $(\mathrm{AOR}=2.503 ; 95 \% \mathrm{CI}=1.539$, 4.071). The likelihood of residents between 30 and 39 years of age increased significantly by the odds of 2.880 to have good practice towards schistosomiasis prevention and control compared to those of 40 years and above $(\mathrm{AOR}=2.880 ; 95 \%$ $\mathrm{CI}=1.559,5.320)$. Male residents were 2.631 times more likely to have good practice towards schistosomiasis prevention and control compared to female residents $(\mathrm{AOR}=2.631 ; 95 \% \mathrm{CI}=1.703,4.067)$.

\section{Discussion}

In the Gambia, this could be the primary study that attempts to demonstrate the impact and nexus of awareness and practices of heads of households with their sociodemographic factors and attitudes regarding the transmission, prevention, and control of schistosomiasis in a scourge rural setting in the Gambia. The findings showed that a larger proportion of household heads/representatives were females, relatively young, and residing within 2 kilometers far away from the river. The results showed more females than males and most people knew something about schistosomiasis with a huge number of them undertaking their water contact activities in unsafe sources of water. While most respondents have heard about schistosomiasis, their awareness of transmission, symptoms, prevention, and control measures remained weak. Rural communities in the Gambia share similar socioeconomic and health profiles; thus, we believe our results are generalizable for the country's entire rural population. More research in other regions should, however, be encouraged.

This study was carried out in endemic areas that are undergoing active surveillance by the Epidemiology and Disease Control Unit of the Ministry of Health, maybe due to the greater proportion of rural dwellers learning about the disease. Furthermore, there were only two MDAs conducted in 2018 using praziquantel and albendazole among children, preschool age, and school-age children from the identified hotspot communities in both Central River Region and Upper River Region of the Gambia. This may explain why very few numbers of participants had good knowledge of the disease. More than half of the participants declared either their experience of the disease through other family members, neighborhood, or personal history of infection, validating the endemicity of these public health problems within these settings. The high burden of the disease among rural dwellers corroborates findings of an earlier study conducted in the Gambia [10]. This calls for more studies among specific vulnerable groups such as women and children from different settings in the Gambia to improve 
TABLE 1: Participants' knowledge of prevention and control of schistosomiasis in CRR, the Gambia, 2019.

\begin{tabular}{|c|c|c|c|c|c|}
\hline \multirow{2}{*}{ Variable } & \multirow{2}{*}{$n(\%)$} & \multicolumn{3}{|c|}{ Knowledge on schistosomiasis } & \multirow{2}{*}{$p$ value } \\
\hline & & Good (14.9\%) & Fair $(30.8 \%)$ & Poor $(54.3 \%)$ & \\
\hline Age of participants & & & & & $0.009^{*}$ \\
\hline Below 30 & $180(47.0)$ & 10.0 & 28.9 & 61.1 & \\
\hline $30-39$ & $77(20.1)$ & 26.0 & 32.5 & 41.6 & \\
\hline 40 and above & $126(32.9)$ & 15.1 & 32.5 & 52.4 & \\
\hline Gender & & & & & 0.164 \\
\hline Male & $188(49.1)$ & 16.0 & 34.6 & 49.5 & \\
\hline Female & $195(50.9)$ & 13.8 & 27.2 & 59.0 & \\
\hline Religion & & & & & $0.049^{*}$ \\
\hline Muslim & $369(96.3)$ & 15.4 & 31.4 & 53.1 & \\
\hline Christian & $14(3.7)$ & 0.0 & 14.3 & 85.7 & \\
\hline River close to your home & & & & & 0.723 \\
\hline Yes & $325(84.9)$ & 15.4 & 31.1 & 53.5 & \\
\hline No & $58(35.1)$ & 12.1 & 29.3 & 53.5 & \\
\hline The distance of the river from your home $(\mathrm{km})(n=376)$ & & & $0.007^{*}$ & & \\
\hline 2.0 and below & $241(62.9)$ & 13.7 & 25.7 & 60.6 & \\
\hline 2.1 and above & $135(35.2)$ & 15.6 & 40.0 & 44.4 & \\
\hline Ever heard about bilharzia & & & & & $<0.001^{*}$ \\
\hline Yes & $267(69.7)$ & 20.2 & 37.1 & 42.7 & \\
\hline No & $116(30.3)$ & 2.6 & 16.4 & 81.0 & \\
\hline Risk factors for contracting bilharzia & & & & & $<0.001^{*}$ \\
\hline Contact with polluted river water with feces/urine & $187(48.8)$ & 23.5 & 47.1 & 29.4 & \\
\hline Body contact with an infected person & $18(4.7)$ & 11.1 & 22.2 & 66.7 & \\
\hline Walking across water barefooted & $15(3.9)$ & 6.7 & 40.0 & 53.3 & \\
\hline Eating unwashed fruits and vegetables & $21(5.5)$ & 9.5 & 23.8 & 66.7 & \\
\hline Do not know & $142(37.1)$ & 5.6 & 10.6 & 83.8 & \\
\hline Source of bilharzia** & & & & & $<0.001^{*}$ \\
\hline From fecal/urine contaminated water/river & $221(57.9)$ & 20.4 & 42.5 & 37.1 & \\
\hline From fecal/urine contaminated soil & $64(16.8)$ & 31.2 & 32.8 & 35.9 & \\
\hline From playing in the rainfall & $37(9.7)$ & 21.6 & 29.7 & 48.6 & \\
\hline Jumping over a fire & $21(5.5)$ & 33.3 & 38.1 & 28.6 & \\
\hline Do not know & $121(31.7)$ & 3.3 & 5.8 & 90.9 & \\
\hline Important methods for prevention of bilharzia** & & & & & $<0.001^{*}$ \\
\hline Proper disposal of human waste & $75(20.2)$ & 14.7 & 33.3 & 52.0 & \\
\hline Boiling water & $80(21.6)$ & 33.8 & 41.2 & 25.0 & \\
\hline Snail eradication & $64(17.3)$ & 32.8 & 31.2 & 35.9 & \\
\hline Proper disposal of general waste & $42(11.3)$ & 7.1 & 45.2 & 47.6 & \\
\hline Do not know & $168(45.3)$ & 8.3 & 22.0 & 69.6 & \\
\hline Complications from bilharzia** & & & & & $<0.001^{*}$ \\
\hline Skin infection & $118(31.1)$ & 22.0 & 37.3 & 44.4 & \\
\hline Poor performance at school & $99(26.1)$ & 16.2 & 39.4 & 44.4 & \\
\hline Poor appetite & $160(42.1)$ & 19.4 & 33.8 & 46.9 & \\
\hline Mood swings & $89(23.4)$ & 20.2 & 36.0 & 43.8 & \\
\hline Do not know & $72(18.9)$ & 1.4 & 12.5 & 86.1 & \\
\hline How to manage bilharzia** & & & & & 0.237 \\
\hline To health-educate people about schistosomiasis & $98(25.6)$ & 13.3 & 38.8 & 48.0 & \\
\hline To go to the hospital for treatment & $146(63.7)$ & 19.9 & 26.7 & 53.4 & \\
\hline Avoid contact with dirty water & $50(76.8)$ & 10.0 & 40.0 & 50.0 & \\
\hline Maintain good personal hygiene & $18(81.5)$ & 16.7 & 22.2 & 61.1 & \\
\hline To use a herb called "Sinjango" & $8(83.6)$ & 0.0 & 37.5 & 62.5 & \\
\hline No response & $9(85.9)$ & 11.1 & 11.1 & 77.8 & \\
\hline I do not know or no idea & $54(85.9)$ & 11.1 & 24.1 & 64.8 & \\
\hline
\end{tabular}

${ }^{*}$ Statistical significance at $p<0.05 .{ }^{* *}$ Multiple responses.

the benefits of targeted schistosomiasis control interventions, particularly education and raising awareness.

Schistosomiasis is progressively widespread in poor rural communities, especially in places where fishing and agricultural activities are predominant. In some countries, the transmission of schistosomiasis may have been hindered through active control programs and/or changing the socioeconomic conditions [21]. 
TABLE 2: Multivariate logistic regression of the factors associated with knowledge on prevention and control of schistosomiasis among study participants at CRR, the Gambia.

\begin{tabular}{|c|c|c|c|c|c|c|}
\hline \multirow{2}{*}{\multicolumn{2}{|c|}{ Knowledge on schistosomiasis }} & \multirow{2}{*}{ B coefficient } & \multirow{2}{*}{ AOR } & \multicolumn{2}{|c|}{$95 \% \mathrm{Cl}$ for $\mathrm{OR}$} & \multirow{2}{*}{$p$ value } \\
\hline & & & & LB & UB & \\
\hline \multirow{14}{*}{ Fair } & Intercept & 0.689 & & & & 0.242 \\
\hline & Age of participants & & & & & \\
\hline & Below 30 & 0.332 & 1.394 & 0.632 & 3.078 & 0.411 \\
\hline & $30-39$ & -0.569 & 0.566 & 0.245 & 1.306 & 0.182 \\
\hline & 40 and above (ref) & $0^{\mathrm{b}}$ & & & & \\
\hline & Ever heard of bilharzia & & & & & \\
\hline & Yes & 1.127 & 3.086 & 0.859 & 11.084 & 0.084 \\
\hline & No (ref) & $0^{\mathrm{b}}$ & & & & \\
\hline & Risk factors for contracting bilharzia & & & & & \\
\hline & Contact with polluted river water with feces/urine & 0.173 & 1.188 & 0.458 & 3.081 & 0.722 \\
\hline & Body contact with an infected person & 0.033 & 1.033 & 0.150 & 7.098 & 0.973 \\
\hline & Walking across water barefooted & 1.341 & 3.821 & 0.377 & 38.765 & 0.257 \\
\hline & Eating unwashed fruits and vegetables & 0.191 & 1.211 & 0.181 & 8.096 & 0.843 \\
\hline & Do not know (ref) & $0^{\mathrm{b}}$ & & & & \\
\hline \multirow{14}{*}{ Poor } & Intercept & 2.010 & & & & 0.000 \\
\hline & Age of participants & & & & & \\
\hline & Below 30 & 0.370 & 1.447 & 0.642 & 3.261 & 0.372 \\
\hline & $30-39$ & -1.105 & 0.331 & 0.133 & 0.825 & $0.018^{*}$ \\
\hline & 40 and above (ref) & $0^{\mathrm{b}}$ & & & & \\
\hline & Ever heard of bilharzia & & & & & \\
\hline & Yes & 2.477 & 11.911 & 3.452 & 41.099 & $<0.001^{*}$ \\
\hline & No $($ ref $)$ & $0^{\mathrm{b}}$ & & & & \\
\hline & Risk factors for contracting bilharzia & & & & & \\
\hline & Contact with polluted river water with feces/urine & -2.295 & 0.101 & 0.042 & 0.242 & $<0.001^{*}$ \\
\hline & Body contact with an infected person & -0.771 & 0.463 & 0.082 & 2.596 & 0.381 \\
\hline & Walking across water barefooted & -0.541 & 0.582 & 0.060 & 5.675 & 0.641 \\
\hline & Eating unwashed fruits and vegetables & -0.712 & 0.491 & 0.085 & 2.819 & 0.425 \\
\hline & Do not know (ref) & $0^{\mathrm{b}}$ & & & & \\
\hline
\end{tabular}

Model adjusted for participants' sex, the distance of river from home, source of bilharzia, prevention methods of bilharzia, complications, communities, and religion. ${ }^{\text {a }}$ The reference category is good knowledge. ${ }^{\mathrm{b}}$ This parameter is set to zero because it is redundant. Statistically significant at $p<0.05$.

TABLE 3: Association between participants' attitude, practice, and knowledge on schistosomiasis prevention and control in CRR, the Gambia, 2019.

\begin{tabular}{|c|c|c|c|c|c|}
\hline \multirow{2}{*}{ Variable } & \multirow{2}{*}{$n(\%)$} & \multicolumn{3}{|c|}{ Knowledge on schistosomiasis } & \multirow{2}{*}{$p$ value } \\
\hline & & Good (14.9\%) & Fair $(30.8 \%)$ & Poor $(54.3 \%)$ & \\
\hline Attitude towards schistosomiasis & & & & & 0.712 \\
\hline Positive & $371(96.9)$ & 15.1 & 30.5 & 54.4 & \\
\hline Negative & $12(3.1)$ & 8.3 & 41.7 & 50.0 & \\
\hline Practice towards schistosomiasis & & & & & 0.270 \\
\hline Good & $221(57.7)$ & 17.2 & 31.2 & 51.6 & \\
\hline Poor & $162(42.3)$ & 11.7 & 30.2 & 58.0 & \\
\hline
\end{tabular}

Schistosomes are a great public health issue in the Gambia, with an estimated prevalence of 4.3 percent nationally and coendemicity prevalence of 38 percent with soil-transmitted helminthiasis with higher males prevalence than females [10]. For countries like the Gambia and Ethiopia where schistosomiasis is endemic, surveillance is intended towards reducing morbidity and arresting the disease's symptoms. The 2017 Gambian national mapping of schistosomes and STHs assessed variability in water, sanitation, and hygiene (WASH) alongside the parasite infections for school children across the country. The parasitological results showed a prevalence of $4.3 \%$ and $2.5 \%$ for schistosomiasis and soiltransmitted helminthiasis, respectively [10].

Overall, these findings are in consistent agreement with earlier studies from other schistosomiasis-endemic countries; a high level of schistosomiasis awareness was reported in Yemen [22], Brazil [23], Nigeria [21], and Western Kenya [24]. In comparison, the Malawi [25] and Zimbabwe reported poor awareness of schistosomiasis [26]. A previous study in Senegal reported low awareness of intestinal schistosomiasis among the population after several years of health education at the Ministry of Health interventions using a variety of communication channels like radio, 
TABle 4: Participants' attitude towards schistosomiasis prevention and control in CRR, the Gambia, 2019.

\begin{tabular}{|c|c|c|c|c|}
\hline \multirow{2}{*}{ Variable } & \multirow{2}{*}{$n(\%)$} & \multicolumn{2}{|c|}{ Attitude towards schistosomiasis } & \multirow{2}{*}{$p$ value } \\
\hline & & Positive $(96.9 \%)$ & Negative $(3.1 \%)$ & \\
\hline Age of participants & & & & 0.374 \\
\hline Below 30 & $180(47.0)$ & 97.2 & 2.8 & \\
\hline $30-39$ & $77(20.1)$ & 98.7 & 1.3 & \\
\hline 40 and above & $126(32.9)$ & 95.2 & 4.8 & \\
\hline Gender & & & & 0.515 \\
\hline Male & $188(49.1)$ & 96.3 & 3.7 & \\
\hline Female & $195(50.9)$ & 97.4 & 2.6 & \\
\hline Religion & & & & 0.493 \\
\hline Muslim & $369(96.3)$ & 96.7 & 3.3 & \\
\hline Christian & $14(3.7)$ & 100 & 0 & \\
\hline River close to your home & & & & 0.723 \\
\hline Yes & $325(84.9)$ & 96.6 & 3.4 & \\
\hline No & $58(35.1)$ & 98.3 & 1.7 & \\
\hline The distance of the river from your home $(\mathrm{km})(n=376)$ & & & & 0.504 \\
\hline 2.0 and below & $241(62.9)$ & 97.1 & 2.9 & \\
\hline 2.1 and above & $135(35.2)$ & 96.3 & 3.7 & \\
\hline
\end{tabular}

* Statistical significance at $p<0.05$.

TABLE 5: Participants' practice towards schistosomiasis prevention and control in CRR, the Gambia, 2019.

\begin{tabular}{|c|c|c|c|c|}
\hline \multirow{2}{*}{ Variable } & \multirow{2}{*}{$n(\%)$} & \multicolumn{2}{|c|}{ Practice towards schistosomiasis } & \multirow{2}{*}{$p$ value } \\
\hline & & Good (57.7\%) & Poor $(42.3 \%)$ & \\
\hline Age of participants & & & & $0.001^{*}$ \\
\hline Below 30 & $180(47.0)$ & 63.3 & 36.7 & \\
\hline $30-39$ & $77(20.1)$ & 66.2 & 33.8 & \\
\hline 40 and above & $126(32.9)$ & 44.4 & 55.6 & \\
\hline Gender & & & & $<0.001^{*}$ \\
\hline Male & $188(49.1)$ & 68.1 & 31.9 & \\
\hline Female & $195(50.9)$ & 47.7 & 52.3 & \\
\hline Religion & & & & 0.611 \\
\hline Muslim & $369(96.3)$ & 75.5 & 42.5 & \\
\hline Christian & $14(3.7)$ & 64.3 & 35.7 & \\
\hline River close to your home & & & & 0.197 \\
\hline Yes & $325(84.9)$ & 59.1 & 40.9 & \\
\hline No & $58(35.1)$ & 50 & 50 & \\
\hline The distance of the river from your home $(\mathrm{km})(\mathrm{n}=376)$ & & & & 0.813 \\
\hline 2.0 and below & $241(62.9)$ & 57.3 & 42.7 & \\
\hline 2.1 and above & $135(35.2)$ & 58.5 & 41.5 & \\
\hline
\end{tabular}

* Statistical significance at $p<0.05$.

TABLE 6: Binary logistic regression of the factors associated with practice towards schistosomiasis prevention and control among study participants at CRR, the Gambia.

\begin{tabular}{|c|c|c|c|c|c|}
\hline \multirow{2}{*}{ Practice towards schistosomiasis } & \multirow{2}{*}{ B coefficient } & \multirow{2}{*}{ AOR } & \multicolumn{2}{|c|}{$95 \% \mathrm{Cl}$ for $\mathrm{OR}$} & \multirow{2}{*}{$p$ value } \\
\hline & & & LB & UB & \\
\hline Age of participants & & & & & $<0.001^{*}$ \\
\hline Below 30 & 0.917 & 2.503 & 1.539 & 4.071 & $<0.001^{*}$ \\
\hline $30-39$ & 1.058 & 2.880 & 1.559 & 5.320 & $0.001^{*}$ \\
\hline 40 and above (ref) & 0 & & & & \\
\hline \multicolumn{6}{|l|}{ Gender of the participants } \\
\hline Male & 0.968 & 2.631 & 1.703 & 4.067 & $<0.001^{*}$ \\
\hline Female (ref) & 0 & & & & \\
\hline Constant & -1.059 & 0.347 & & & 0.002 \\
\hline
\end{tabular}

Model adjusted for the proximity of the river from home. ref = reference category. Statistically significant at $p<0.05$. 
television, and posters [27]. It was proposed that neighbourhoods and schools should be incorporated into health education outreach programs to ensure the fact that the awareness across the community is distributed over a period of time [24].

4.1. Study Limitations. Like any other studies, our population of interest were household heads/members either male or female; the implications for study findings generalizability to only household heads, women of childbearing age, or males could be limited. However, the sample size used for the study was computed using the Cochrane formula for descriptive studies. Conversely, the name of a cross-sectional study for causal inferences cannot be made from the results reported. Yet another notable limitation was the lack of adjustment for certain sociodemographic factors.

\section{Conclusions}

The study revealed that information about the cause, transmission, symptoms, prevention, and control of schistosomiasis in rural communities was not sufficient and will be a challenging barrier to the elimination of schistosomiasis from these populations. The reported awareness level about schistosomiasis continues to be very low, and this may mean that a great deal of the government's commitment to schistosomiasis control programmes is extremely necessary. In addition to mass drug administration, school and community health education concerning good personal hygiene and good sanitary practices is crucial among these populations in order to significantly reduce the spread and morbidity of schistosomiasis in rural communities in the Gambia. Continued health education is vital to raising public awareness of schistosomiasis and enables symptomatic individuals to receive treatment with praziquantel. The diagnostic and treatment capacity of government health facilities with regard to schistosomiasis needs to be improved, diagnosis and treatment costs subsidized, alternative water sources provided, and health education programs developed for both community and school settings.

\section{Abbreviations}

CRR: Central River Region

MDA: Mass drug administration

WHO: World Health Organization.

\section{Data Availability}

The data used to support the findings of this study are included in the article. The datasets analyzed during the study are available upon reasonable request from the school administration.

\section{Ethical Approval}

Prior to the study, a permission was received from community leaders, the Ministry of Health, the Gambia. The Gambia College Research Committee provided ethical approval of the research project. The people were sensitized about the nature of the study and study objectives in local languages (Mandinka, Fula, and Wolof).

\section{Consent}

The research participants provided formal, informed consent for their participation in the study. Participation was entirely voluntary. Written informed consent was obtained from each study participant for their enrolment into the study.

\section{Conflicts of Interest}

The authors declare that they have no conflicts of interest regarding the publication of this paper.

\section{Authors' Contributions}

$\mathrm{AB}, \mathrm{MB}, \mathrm{MN}$, and ET conceptualized the study and prepared the study design. $\mathrm{AB}, \mathrm{MB}$, and $\mathrm{BK}$ reviewed the literature. $\mathrm{AB}, \mathrm{MB}, \mathrm{JT}, \mathrm{MN}, \mathrm{BK}, \mathrm{ET}, \mathrm{SLSK}, \mathrm{SOS}, \mathrm{YJ}, \mathrm{LD}, \mathrm{MB}$, and MG undertook fieldwork. ET and MB performed data input. AB performed data analysis, wrote the results, discussed the findings, and wrote the initial draft of the manuscript. AB and SPSJ critically reviewed the manuscript for its intellectual content. $\mathrm{AB}$ had the final responsibility of submission for publication. All authors read and approved the final manuscript.

\section{Acknowledgments}

The authors are grateful to the fathers, mothers, and children who participated in the study. Special thanks are due to the administration of Bansang Senior Secondary School, Armitage Senior Secondary School, Governor's Office-CRR, youth community leaders, village heads (alkalos), and the village health workers for their assistance in the mobilization of the participants from the communities under the study. The authors are grateful to the administration of Bansang General Hospital and School of Enrolled Nurses for their help in hosting their team and using their facilities during the study period. The authors finally acknowledge the School of Public Health students for their assistance in data collection and Gambia College administration for logistical support. The project was partly funded by the school alumni in the form of donations during our door-to-door visits to some public and private institutions.

\section{References}

[1] A. C. Clements, S. Firth, R. Dembelé et al., "Use of Bayesian geostatistical prediction to estimate local variations in Schistosoma haematobium infection in western Africa," Bulletin of the World Health Organization, vol. 87, no. 12, pp. 921-929, 2009.

[2] World Health Organization, "Schistosomiasis 2019 fact sheets," 2019, https://www.who.int/news-room/fact-sheets/ detail/schistosomiasis.

[3] P. M. Boko, M. Ibikounle, A. Onzo-Aboki et al., "Schistosomiasis and soil transmitted helminths distribution in Benin: 
a baseline prevalence survey in 30 districts," PLoS One, vol. 11, no. 9, 2016.

[4] L. Drudge-Coates and B. Turner, "Schistosomiasis-an endemic parasitic waterborne disease," The British Journal of Nursing, vol. 22, no. 9, pp. S10-S14, 2013.

[5] B. Chala and W. Torben, "An epidemiological trend of urogenital schistosomiasis in Ethiopia," Frontiers in Public Health, vol. 6, p. 60, 2018.

[6] D. G. Colley, A. L. Bustinduy, W. E. Secor, and C. H. King, "Human schistosomiasis," The Lancet, vol. 383, no. 9936, pp. 2253-2264, 2014.

[7] A. L. Araujo Navas, N. A. S. Hamm, R. J. Soares Magalhães, and A. Stein, "Mapping soil transmitted helminths and schistosomiasis under uncertainty: a systematic review and critical appraisal of evidence," PLoS Neglected Tropical Diseases, vol. 10, no. 12, 2016.

[8] W. E. Secor, "Water-based interventions for schistosomiasis control," Pathogens and Global Health, vol. 108, no. 5, pp. 246-254, 2014.

[9] W. K. Redekop, E. J. Lenk, M. Luyendijk et al., “The socioeconomic benefit to individuals of achieving the 2020 targets for five preventive chemotherapy neglected tropical diseases," PLoS Neglected Tropical Diseases, vol. 11, no. 1, 2017.

[10] Y. Camara and B. Sanneh, "Assessment of the endemicity status of schisotsomiasis and soil-transmitted helminthiasis in the Gambia," BMJ Global Health, vol. 2, no. 2, 2017.

[11] J. W. Macharia, Z. W. Ng'ang'a, and S. M. Njenga, "Factors influencing community participation in control and related operational research for urogenital schistosomiasis and soiltransmitted helminths in rural villages of Kwale County, coastal Kenya," Pan African Medical Journal, vol. 24, 2016.

[12] D. A. P. Bundy, L. J. Appleby, M. Bradley et al., "100 Years of mass deworming programmes: a policy perspective from the world bank's disease control priorities analyses," in Advances in Parasitology, vol. 100, pp. 127-154, Elsevier, Amsterdam, Netherlands, 2018.

[13] H. Sacolo, M. Chimbari, and C. Kalinda, "Knowledge, attitudes and practices on Schistosomiasis in sub-Saharan Africa: a systematic review," BMC Infectious Diseases, vol. 18, no. 1, p. 46, 2018.

[14] R. N. Bronzan, A. M. Dorkenoo, Y. M. Agbo et al., "Impact of community-based integrated mass drug administration on schistosomiasis and soil-transmitted helminth prevalence in Togo," PLoS Neglected Tropical Diseases, vol. 12, no. 8, 2018.

[15] E. J. Schatz, “"Taking care of my own blood"”: older women's relationships to their households in rural South Africa," Scandinavian Journal of Public Health, vol. 35, no. 69, pp. 147-154, 2007.

[16] Gambia Bureau of Statistics (GBoS), Gambia Demographic Health Survey, Gambia Bureau of Statistics (GBoS), Banjul, Gambia, 2013.

[17] M. S. Jaiteh, Climate Change and Development in the Gambia: Challenges to Ecosystem Goods and Services, The Earth Institute, Columbia University, New York, NY, USA, 2011, http://www.columbia.edu/ msj42/pdfs/ClimateChange DevelopmentGambia_small.pdf.

[18] Humanitarian Country Team, Humanitarian Needs Overview: The Gambia, 2015, https://reliefweb.int/sites/reliefweb.int/ files/resources/2016_TheGambia_HNO.pdf.

[19] Gambia Bureau of Statistics (GBOS), The Gambia Multiple Indicator Cluster Survey 2018 Survey Finding Report, Gambia Bureau of Statistics (GBOS), Banjul, Gambia, 2019.

[20] Ministry of Basic \& Secondary Education and United Nations Children's Fund, National Study of Out-Of-School Children in the Gambia, 2017, https://www.unicef.org/gambia/media/ 636/file/National-Study-of-Out-of-School-Children-in-TheGambia-2017.pdf.

[21] S. Dawaki, H. M. Al-Mekhlafi, I. Ithoi et al., "The menace of schistosomiasis in Nigeria: knowledge, attitude, and practices regarding schistosomiasis among rural communities in kano state," PLoS One, vol. 10, no. 11, 2015.

[22] H. Sady, H. M. Al-Mekhlafi, W. M. Atroosh et al., "Knowledge, attitude, and practices towards schistosomiasis among rural population in Yemen," Parasites \& Vectors, vol. 8, no. 1, p. 436, 2015.

[23] H. Kloos, R. Correa-Oliveira, H. F. Oliveira Quites, M. C. Caetano Souza, and A. Gazzinelli, "Socioeconomic studies of schistosomiasis in Brazil: a review," Acta Tropica, vol. 108, no. 2-3, pp. 194-201, 2008.

[24] R. M. Musuva, M. Omedo, W. E. Secor et al., "Community knowledge, attitudes and practices on schistosomiasis in western Kenya-the SCORE project," The American Journal of Tropical Medicine and Hygiene, vol. 90, no. 4, pp. 646-652, 2014.

[25] H. Poole, D. J. Terlouw, A. Naunje et al., "Schistosomiasis in pre-school-age children and their mothers in Chikhwawa district, Malawi with notes on characterization of schistosomes and snails," Parasites \& Vectors, vol. 7, no. 1, p. 153, 2014.

[26] N. Midzi, S. Mtapuri-Zinyowera, M. P. Mapingure et al., "Knowledge attitudes and practices of grade three primary schoolchildren in relation to schistosomiasis, soil transmitted helminthiasis and malaria in Zimbabwe," BMC Infectious Diseases, vol. 11, no. 1, p. 169, 2011.

[27] S. Sow, S. J. Vlas, A. Mbaye, K. Polman, and B. Gryseels, "Low awareness of intestinal schistosomiasis in northern Senegal after 7 years of health education as part of intense control and research activities," Tropical Medicine and International Health, vol. 8, no. 8, pp. 744-749, 2003. 